\title{
Phospholipase C-mediated hydrolysis of phosphatidylcholine is activated by muscarinic agonists
}

\author{
Maria T. DIAZ-MECO, Pilar LARRODERA, Monica LOPEZ-BARAHONA, Maria E. CORNET, \\ Pedro G. BARRENO and Jorge MOSCAT* \\ Medicina y Cirugia Experimental, Hospital General 'Gregorio Maranon', Dr. Esquerdo 46, 28007 Madrid, Spain
}

\begin{abstract}
The phospholipase C-catalysed breakdown of inositol-containing phospholipids is an important source of diacylglycerol in cells stimulated by several agonists. However, recent experimental evidence suggests that major phospholipids such as phosphatidylcholine may also be substrates of the phosphodiesteratic hydrolysis activated by hormones, growth factors and oncogene products. We show here that stimulation of muscarinic agonists activates the release of phosphocholine, which, along with diacylglycerol, is a metabolic product of phospholipase C-mediated hydrolysis of phosphatidylcholine. Fluoroaluminates mimic this muscarinic effect, strongly suggesting that carbachol-activated release of phosphocholine may be mediated by a guanine-nucleotide-binding protein. Evidence for this was obtained from experiments using permeabilized cells in which non-hydrolysable analogues of GTP activated phosphocholine release synergistically with carbachol.
\end{abstract}

\section{INTRODUCTION}

A number of studies have shown the importance of phospholipid metabolism in the control of cellular activation $[1,2]$. Most of the work has been focused on phosphoinositide (PI) turnover [3], whereby phospholipase C (PLC)-mediated hydrolysis of inositol-containing phospholipids (PtdInsPs) generates at least two second messengers [3]: inositol 1,4,5-trisphosphate and diacylglycerol (DAG). The former participates, in collaboration with its metabolic product (inositol 1,3,4,5tetrakisphosphate) in the control of cytosolic $\mathrm{Ca}^{2+}$ levels [4]. DAG, on the other hand, is an important cofactor for protein kinase $\mathrm{C}(\mathrm{PKC})$ [5], and a possible source of arachidonic acid [6,7]. Cytosolic $\mathrm{Ca}^{2+}$ and PKC appear to be key steps in signal-transduction pathways that regulate important cellular functions, including secretion $[8,9]$, cell growth [10] and tumour transformation [11].

More recently, it has been shown that part of the DAG produced in cells stimulated by different agonists did not arise from the phosphodiesteratic hydrolysis of PtdIns $P$ s [12]. This would indicate that sources of DAG other than PI turnover may be stimulated by some ligands. Interestingly, PLC-catalysed breakdown of phosphatidylcholine (PtdCho) and phosphatidylethanolamine has been reported to occur in response to several stimuli ranging from hormones and growth factors [13-15] to oncogene products [16]. This would indicate that not only PtdIns $P$ s but also major phospholipids, such as PtdCho and phosphatidylethanolamine, could contribute to the DAG generated during cellular stimulation.

The activation of muscarinic cholinergic receptors results in the triggering of various signal-transduction pathways. These include: inhibition of adenylate cyclase (AC) through a G-protein sensitive to pertussis toxin $\left(G_{i}\right)$, and activation of a PI-specific PLC [17].
Some stimulants of PI turnover, such as $\alpha$-adrenergic agonists or the platelet-derived growth factor, have been shown to activate PtdCho hydrolysis [13,15]. It is not known whether this phospholipid-degradative pathway is activated after stimulation of muscarinic cholinergic receptors. We show here that activation of this type of receptors is associated with the phosphodiesteratic hydrolysis of PtdCho, most probably through a Gprotein. These results increase the list of transducing cascades triggered by muscarinic agonists, and further suggest the importance of this novel phospholipiddegradative pathway in cell activation.

\section{MATERIALS AND METHODS}

\section{Cell cultures}

Swiss 3T3 fibroblasts (passage 123) were purchased from Flow Laboratories and cultured in Dulbecco's modified Eagle's medium supplemented with $10 \%$ (v/v) fetal-bovine serum, penicillin (100 units $/ \mathrm{ml}) /$ streptomycin $(100 \mu \mathrm{g} / \mathrm{ml})$ and $2 \mathrm{~mm}-\mathrm{L}$-glutamine. Cells were grown in standard tissue culture flasks in a humidified air $/ \mathrm{CO}_{2}(19: 1)$ incubator at $37^{\circ} \mathrm{C}$.

\section{Analysis of products of phosphodiesteratic hydrolysis of PtdCho}

Cells were labelled for $48 \mathrm{~h}$ with $2 \mu \mathrm{Ci}$ of [methyl${ }^{14} \mathrm{C}$ ]choline (Amersham International; sp. radioactivity $50-60 \mathrm{mCi} / \mathrm{mmol}) / \mathrm{dish}$. The last $24 \mathrm{~h}$ of labelling was performed in serum-free medium supplemented with transferrin $(5 \mu \mathrm{g} / \mathrm{ml})$ and $\mathrm{Na}_{2} \mathrm{SeO}_{3}(1 \mu \mathrm{M})$. Afterwards, medium was removed and label-free medium without serum was added. After a 30 min equilibration, cells were treated with the corresponding drugs for different times. Reactions were stopped by removing the supernatants,

Abbreviations used: AC, adenylate cyclase; ACho, acetylcholine; CCho, carbamoylcholine (carbachol); DAG, diacylglycerol; DMPP, 1,1dimethyl-4-phenylpiperazonium; GTP[S], guanosine $5^{\prime}$-[ $\gamma$-thio]triphosphate; GDP[S], guanosine $5^{\prime}$-[ $\beta$-thio]diphosphate; $\mathbf{G}_{i}$, pertussis-toxin-sensitive guanine-nucleotide-binding protein; PI, phosphoinositide; PKC, protein kinase C; PCho, phosphocnoline; PtdCho, phosphatidylcholine; PtdIns Ps, phosphatidylinositol phosphates; PLC, phospholipase C.

* To whom correspondence should be addressed. 
and adding ice-cold methanol to cells. The supernatants were centrifuged at $4{ }^{\circ} \mathrm{C}$ to remove possible detached cells, and the presence of extracellular phosphocholine (PCho) was determined by t.l.c. [18], followed by autoradiography of plates in which standards corresponding to the different water-soluble choline metabolites were included. Afterwards, radioactive spots were scraped off and quantified by liquid-scintillation counting. Methanolic cell extracts were fractionated into chloroform and aqueous phases as previously described [19]. The presence and levels of intracellular PCho were evaluated in the aqueous phases by t.l.c. as described above.

\section{Cyclic AMP assay}

Cells grown in $22 \mathrm{~mm}$-diameter plastic culture dishes (Costar, U.S.A.) were made quiescent by $24 \mathrm{~h}$ of serum starvation. After incubation for $10 \mathrm{~min}$ in the presence of 3-isobutyl-1-methylxanthine (final concn. $1 \mathrm{~mm}$ ), cholera toxin $(100 \mathrm{ng} / \mathrm{ml})$ was added and the incubation was continued for another $10 \mathrm{~min}$. Afterwards, cells were treated with different agonists for $3 \mathrm{~min}$, and reactions were terminated by adding trichloroacetic acid $(10 \%$, $\mathrm{w} / \mathrm{v})$. In some experiments cells were treated with pertussis toxin $(400 \mathrm{ng} / \mathrm{ml})$ for $24 \mathrm{~h}$. Cyclic AMP in trichloroacetic acid-soluble extracts was determined with a commercially available radioimmunoassay kit (NEN, Boston, MA, U.S.A.).

Measurement of PCho production in permeabilized cells

Cells labelled as above were washed twice with $\mathrm{Ca}^{2+}$ and $\mathrm{Mg}^{2+}$-free phosphate-buffered saline $(0.5 \mathrm{mM}$ $\mathrm{MgCl}_{2} / 0.3 \mathrm{~mm}-\mathrm{KCl} / 137 \mathrm{~mm}-\mathrm{NaCl} / 8 \mathrm{mM}^{-\mathrm{Na}_{2}} \mathrm{HPO}_{4} /$ $1.5 \mathrm{mM}-\mathrm{KH}_{2} \mathrm{PO}_{4}, \mathrm{pH}$ 7.4) followed by two washes with high-K ${ }^{+}$medium $\left(\mathrm{KCl}, 140 \mathrm{mM} ; \mathrm{NaCl}, 20 \mathrm{mM} ; \mathrm{MgCl}_{2}\right.$, $2 \mathrm{mM}$; ATP, $2 \mathrm{~mm}$; Pipes, $20 \mathrm{~mm}$; EGTA, $1 \mathrm{~mm}$; pH 6.8) with a free $\mathrm{Ca}^{2+}$ concentration of $0.3 \mu \mathrm{M}$, before addition of digitonin $(50 \mu \mathrm{g} / \mathrm{ml})$ for a period of $4 \mathrm{~min}$ at $37^{\circ} \mathrm{C}$. The digitonin was removed by washing cells twice with high- $\mathrm{K}^{+}$medium, after which agonists were added for different times.

\section{RESULTS}

In order to examine whether cholinergic stimulation was associated with PLC-mediated hydrolysis of PtdCho, the following experiment was performed. Swiss 3T3 fibroblasts were labelled with $\left[{ }^{14} \mathrm{C}\right]$ choline, as described in the Materials and methods section. Afterwards, label was washed out and cell cultures were equilibrated for $20 \mathrm{~min}$ in label-free medium, after which $20 \mathrm{~mm}$ acetylcholine (ACho) was added and reactions were stopped at different times. Under these conditions, PCho released both extracellularly and into the intracellular milieu was measured. Fig. $1 a$ shows that ACho induces a significant, although transient, release of PCho to the extracellular medium. Thus maximal values for this parameter were observed between 1 and 2 min after agonist addition, and basal values were attained by $10 \mathrm{~min}$. In the same incubations, changes in PCho intracellular levels were measured. Results shown in Fig. 1(b) clearly indicate that little or no alterations in this parameter were observed in cells stimulated by ACho. A very similar response was observed when $\left[{ }^{14} \mathrm{C}\right]$ cholinelabelled Swiss 3T3 fibroblasts were stimulated with carbachol (carbamoylcholine; CCho), another potent cholinergic stimulant (Figs. $1 c$ and $1 d$ ).

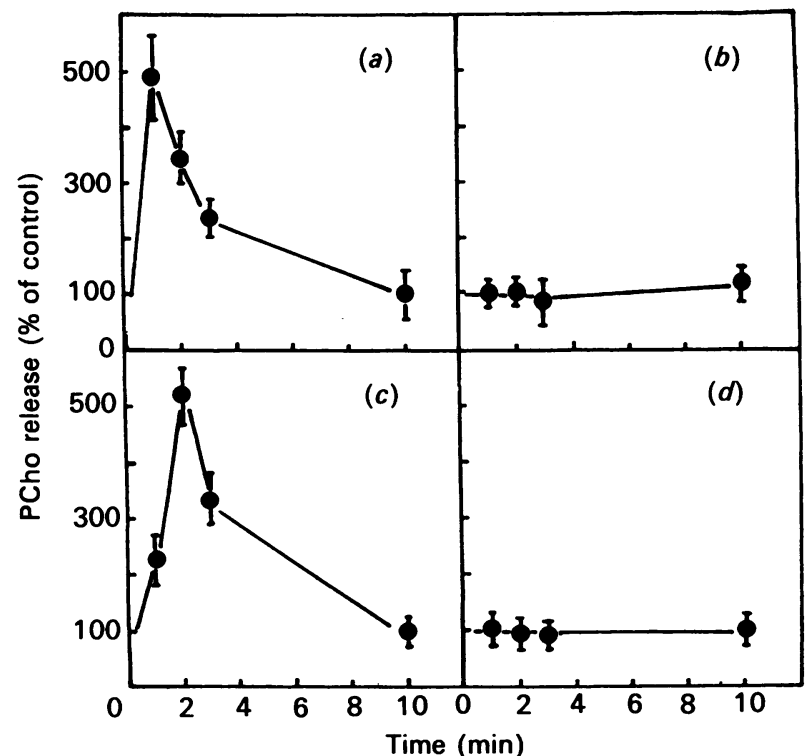

Fig. 1. Time course of the release of $\mathrm{PCh}$ in response to cholinergic stimulation

Cells were labelled and equilibrated as described in the Materials and methods section. Afterwards, they were incubated either in the absence (controls) or in the presence of ACho (20 mM), and PCho released either to extracellular (a) or to intracellular $(b)$ media was determined. In cultures in parallel, labelled cells were stimulated with CCho $(20 \mathrm{~mm})$ and the release of PCho to the extracellular (c) and to the intracellular $(d)$ media was measured. Results are means \pm S.D. of three independent experiments with incubations in duplicate. Levels of extracellular and intracellular PCho in controls were $320 \pm 41$ and $6500 \pm 420$ c.p.m./well.

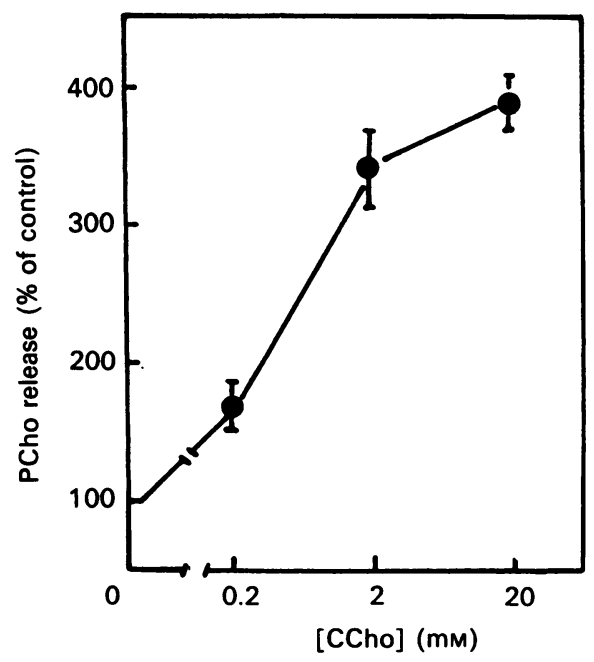

Fig. 2. Dose-response of the effect of CCho on the release of PCho

$\left[{ }^{14} \mathrm{C}\right]$ Choline-labelled cells were stimulated with increasing concentrations of CCho for 2 min, after which reactions were stopped and PCho released was determined. Controls were incubated with carrier buffer without agonist. Results are means \pm S.D. of three independent experiments with incubations in duplicate. Control levels of extracellular PCho were $280 \pm 30$ c.p.m./well. 
Results shown in Fig. 2 indicate that the effect of CCho on the release of PCho is a dose-dependent phenomenon. These data also show that the concentration of agonists resulting in $50 \%$ of the maximal effects was $0.5 \mathrm{~mm}$.

In additional experiments we examined the pharmacology of cholinergic-stimulated PCho release. Atropine is a well-known antagonist of muscarinic receptors, and hence is a useful tool to investigate the involvement of this type of receptors in CCho-stimulated release of PCho. Results shown in Fig. 3 indicate that preincubation of cells in the presence of atropine $(400 \mu \mathrm{M})$ for $10 \mathrm{~min}$ before agonist addition abolished CCho-induced release of PCho. These results suggest that the effects of this stimulant on the phosphodiesteratic degradation of PtdCho takes place by stimulation of muscarinic receptors. In order to assess further the pharmacological specificity of CCho actions on PtdCho metabolism, labelled cell cultures were activated, for different times, either with muscarinic (i.e. muscarine) or nicotine (i.e. 1,1-dimethyl4-phenylpiperazonium; DMPP) agonists, after which PCho release was measured. Results shown in Fig. 4 clearly indicate that whereas muscarine produced a dramatic release of PCho, little or no alteration was observed in this parameter when cells were challenged with DMPP. Taken together, these results indicate that muscarinic stimulation of Swiss 3T3 fibroblasts is associated with PLC-mediated degradation of PtdCho.

$\mathrm{AC}$ inhibition is a well-known effect of muscarinic stimulation [17]. In order to demonstrate the presence of functional muscarinic receptors in the cell system used here, the following experiments were carried out. Cells were either untreated or treated with cholera toxin (which ADP-ribosylates the $\alpha$-subunit of $\mathrm{G}_{\mathrm{s}}$ (stimulatory Gprotein), leading to the permanent activation of $\mathrm{AC}$; see ref. [20]) for $10 \mathrm{~min}$ before the addition of CCho (20 mM) or muscarine $(2 \mathrm{mM})$. Cyclic AMP levels in cholera-

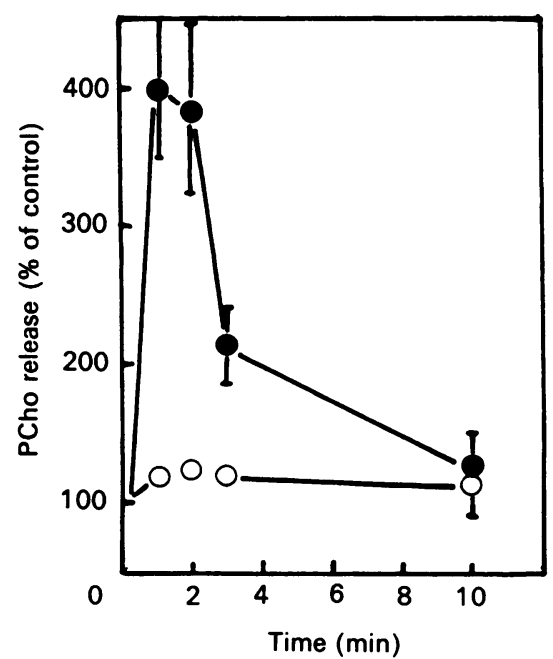

Fig. 3. Effect of atropine on the CCho-stimulated release of PCho

$\left[{ }^{14} \mathrm{C}\right]$ Choline-labelled cells were either untreated $(O)$ or treated $(O)$ with atropine $(400 \mu \mathrm{M})$ for $10 \mathrm{~min}$ before addition of CCho (20 mM). Reactions were stopped at different times after the agonist challenge, and PCho released was determined. Results are means \pm S.D. of three independent experiments with incubations in duplicate. PCho levels in controls were $300 \pm 25$ c.p.m./well.

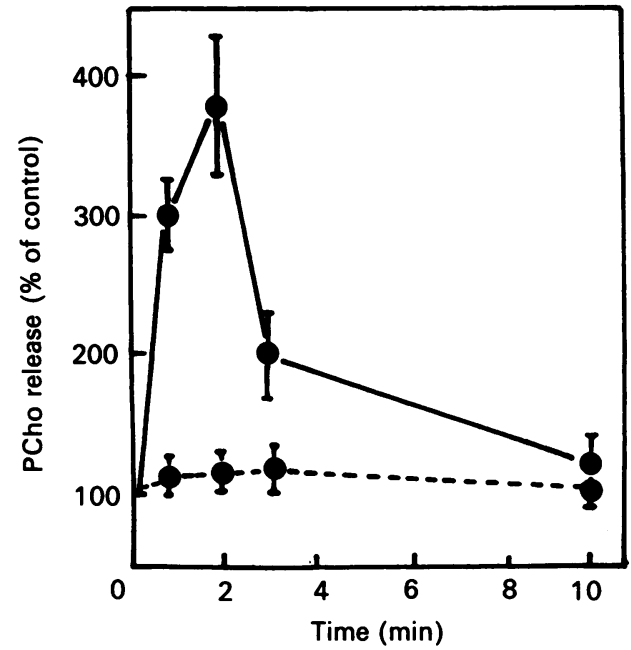

Fig. 4. Time course of the effect of different cholinergic stimulants on the release of PCho

Labelled cells were incubated either in the absence (control) or in the presence of $1 \mathrm{~mm}$-muscarine (-) or $1 \mathrm{~mm}$ DMPP (---). At different times after addition of agonists, reactions were terminated and PCho released determined. Results are means \pm S.D. of three independent experiments with incubations in duplicate. PCho levels in controls were $320 \pm 25$ c.p.m./well.

toxin-treated cells were $0.42 \pm 0.02 \mathrm{pmol} /$ well, whereas untreated cultures had $0.10 \pm 0.01 \mathrm{pmol}$ of cyclic AMP/well. The addition of CCho to cholera-toxintreated cells decreased the production of cyclic AMP to $0.15 \pm 0.02 \mathrm{pmol} /$ well, whereas addition of this agonist to cholera-toxin-treated cells which had previously been exposed to atropine $(400 \mu \mathrm{M})$ for $10 \mathrm{~min}$ decreased cyclic AMP only to $0.34 \pm 0.03 \mathrm{pmol} / \mathrm{well}$. This indicates that atropine blocks the ability of CCho to inhibit choleratoxin-activated $\mathrm{AC}$; this is in agreement with the notion that CCho is acting through a muscarinic receptor. In this regard, it is noteworthy that muscarine ( $2 \mathrm{~mm})$ addition to cholera-toxin-treated cells decreased cyclic AMP production to $0.17 \pm 0.02 \mathrm{pmol} /$ well. The effect of muscarinic agonists on $A C$ is mediated by $G_{i}$ [17]. The ADP-ribosylation of the $\alpha$-subunit of this G-protein, by treatment with pertussis toxin, uncouples the effect of muscarinic receptors on AC [21]. Interestingly, CCho addition to pertussis-toxin-treated cells was unable to inhibit cyclic AMP production induced by cholera toxin (results not shown).

Recent experimental evidence indicates that muscarinic stimulation of PI-specific PLC is mediated by a still uncharacterized G-protein [22]. Therefore it was decided to investigate whether this sort of transducing protein could possibly be involved in muscarinic stimulation of PtdCho-specific PLC. To address this point, we took advantage of the capability of fluoroaluminates to stimulate G-proteins in the absence of agonists, in intact cells. Thus $\left[{ }^{14} \mathrm{C}\right]$ choline-labelled cells were incubated in the presence of $\mathrm{NaF}(5 \mathrm{mM})$ plus $\mathrm{AlCl}_{3}(10 \mu \mathrm{M})$, which gives rise to $\mathrm{AlF}_{4}^{-}$, for different times, after which reactions were stopped and PCho release was measured. Results shown in Fig. 5 indicate that $\mathrm{AlF}_{4}{ }^{-}$is a potent activator of the release of PCho. Interestingly, compared with the effect of CCho, the response to $\mathrm{AlF}_{4}{ }^{-}$was not transient, 


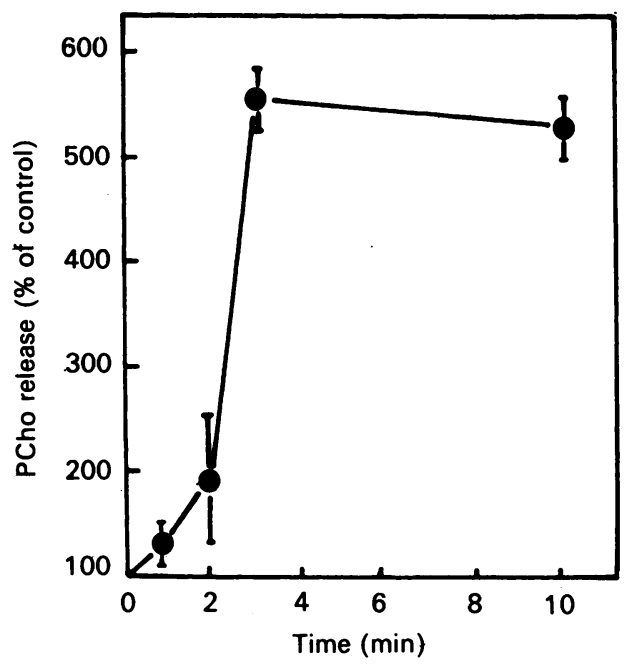

Fig. 5. Time course of $\mathrm{PCho}$ release in response to $\mathrm{NaF}$ plus $\mathrm{AlCl}_{3}$

$\left[{ }^{14} \mathrm{C}\right]$ Choline-labelled cells were stimulated with $5 \mathrm{mM}-\mathrm{NaF}$ plus $10 \mu \mathrm{M}-\mathrm{AlCl}_{3}$ for different times. Incubations were stopped as described and PCho released was determined. Results are means \pm S.D. of three independent experiments with incubations in duplicate. Levels of PCho in controls were $350 \pm 35$ c.p.m./well.

but sustained, at least up to $20 \mathrm{~min}$ after the stimulant addition. When cells were treated with CCho $(20 \mathrm{mM})$ in the presence of $\mathrm{NaF}(5 \mathrm{mM})$, a transient release of PCho was observed (results not shown), which suggests that the sustained activation of PtdCho-PLC detected in response to $\mathrm{AlF}_{4}^{-}$was not due to a hypothetical inhibition of extracellular degradation of PCho. The activating effect of $\mathrm{NaF}$ plus $\mathrm{AlCl}_{3}$ on the release of extracellular PCho was dose-dependent. Fig. 6 shows the absolute requirement for $\mathrm{AlCl}_{3}$ (which by itself was without effect) for NaF to stimulate PLC-mediated degradation of PtdCho. These data clearly indicate that the ability of $\mathrm{NaF}$ plus $\mathrm{AlCl}_{3}$ to increase the release of PCho in the cell system used here cannot be ascribed to artifactual effects of $\mathrm{NaF}$ owing to its phosphataseinhibitory properties, but are a consequence of the direct activation of a G-protein.

In order to demonstrate that muscarinic stimulation of PtdCho-PLC is actually mediated by a G-protein, the following experimental approach was used. $\left[{ }^{14} \mathrm{C}\right]$ Cholinelabelled cells were permeabilized with digitonin as described in the Materials and methods section, after which they were incubated with CCho $(20 \mathrm{~mm})$ for $2 \mathrm{~min}$ either in the absence or in the presence of GTP[S] or GDP[S], which are non-hydrolysable analogues of GTP and GDP respectively. Results shown in Table 1 indicate that CCho addition to permeabilized cells induced little or no stimulation of PCho release. However, a significant production of PCho was detected after addition of GTP[S], but not of GDP[S] (Table 1). Interestingly, the presence of GTP[S]increased PCho release synergistically with CCho. This effect was not detected when incubations were carried out in the presence of GDP[S] plus CCho (Table 1). All these results clearly indicate that muscarinic stimulation of PtdCho-PLC is actually mediated by a Gprotein. It was conceivable that this G-protein-mediated effect could be sensitive to pertussis-toxin treatment.

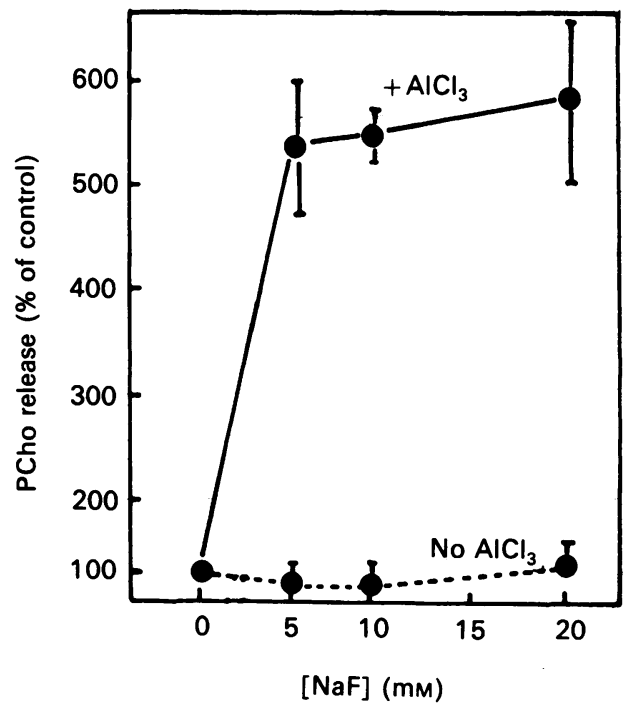

Fig. 6. Effect of the presence of $\mathrm{AlCl}_{3}$ on the release of PCho in response to different concentrations of $\mathrm{NaF}$

$\left[{ }^{14} \mathrm{C}\right]$ Choline-labelled cells were incubated for $3 \mathrm{~min}$ with different concentrations of $\mathrm{NaF}$ either in the absence $(---)$ or in the presence (-) of $\mathrm{AlCl}_{3}$. Reactions were terminated and PCho levels measured as described. Results are means \pm S.D. of three independent experiments with incubations in duplicate. PCho levels in controls were $420 \pm 36$ c.p.m./well.

Table 1. Synergistic stimulation of PCho release by $\mathrm{CCho}$ and GTP[S]

$\left[{ }^{14} \mathrm{C}\right]$ Choline-labelled cells were permeabilized with digitonin as described in the Materials and methods section. Incubations were performed for $2 \mathrm{~min}$ after the addition of different stimulants, after which PCho release was measured. Results are means \pm S.D. of three independent experiments with incubations in duplicate.

\begin{tabular}{lc}
\hline Additions & Release (c.p.m./well) \\
\hline None & $300 \pm 40$ \\
CCho $(20 \mathrm{mM})$ & $370 \pm 30$ \\
GTP[S] $(100 \mu \mathrm{M})$ & $430 \pm 40$ \\
GDP[S] $(100 \mu \mathrm{M})$ & $280 \pm 25$ \\
CCho $(20 \mathrm{mM})+\mathrm{GTP}[\mathrm{S}](100 \mu \mathrm{M})$ & $660 \pm 35$ \\
CCho $(20 \mathrm{mM})+\mathrm{GDP}[\mathrm{S}](100 \mu \mathrm{M})$ & $305 \pm 25$ \\
\hline
\end{tabular}

To address this point, $\left[{ }^{14} \mathrm{C}\right]$ choline-labelled cells were incubated for $24 \mathrm{~h}$ with $400 \mathrm{ng}$ of pertussis toxin/ml, after which cells were stimulated with CCho $(20 \mathrm{~mm})$ for different times. Results from these experiments (not shown) indicate that CCho-stimulated PCho release was insensitive to a previous treatment with pertussis toxin. The fact that pertussis toxin abolished the ability of CCho to inhibit cholera-toxin-activated cyclic AMP production (see above) indicates that the lack of effect of pertussis-toxin treatment on CCho-induced PCho release is not due to the inability of pertussis toxin to ADPribosylate $G_{i}$ under the conditions of the assay used here.

\section{DISCUSSION}

The results presented here clearly demonstrate that stimulation of muscarinic cholinergic receptors activates 
a PtdCho-specific PLC in Swiss 3T3 fibroblasts. This cell system has previously been shown to be suitable for studies of signal transduction involving muscarinic receptors [23,24]. Furthermore, preliminary results indicate that muscarinic agonists induce in bovine chromaffin cells (J. Moscat, M. T. Miras-Portugal \& M. T. Diaz-Meco, unpublished work), which have been shown to possess functional muscarinic receptors [25], a similar response in terms of PCho release to that described here in Swiss 3T3 fibroblasts. One of the signaltransduction pathways activated in response to this type of cholinergic agonists includes the inhibition of AC through a pertussis-toxin-sensitive G-protein $\left(\mathrm{G}_{\mathbf{i}}\right)$. As a control for the presence of actual functional muscarinic receptors in Swiss 3T3 fibroblasts, we showed that CCho was able to inhibit cholera-toxin-activated AC in Swiss 3T3 fibroblasts. This effect of CCho was abolished by addition of atropine to the cell cultures, and was not detected in pertussis-toxin-treated fibroblasts. All these data clearly demonstrate the presence of functional muscarinic receptors in these cells. Therefore this supports our suggestion that $\mathrm{CCho}$ and ACho activation of PtdCho-specific PLC in Swiss 3T3 fibroblasts is actually mediated by the stimulation of muscarinic receptors.

Besides inhibiting AC, muscarinic stimulation has been shown to be associated with a significant increase in the release of metabolic products of PI turnover [26]. In our cellular system we observed little or no change in the release of inositol phosphates in response to stimulation with CCho (results not shown). A similar lack of activation of PI-specific PLC in response to muscarinic stimulation has been found in the neuroblastoma $\times$ glioma cell line NG 108-15 [17]. These cells, however, respond to the muscarinic challenge by efficiently inhibiting AC. Contrarily, the human astrocytoma cell line $1321 \mathrm{~N}$ does not respond to muscarinic activation by inhibiting $\mathrm{AC}$, but does, however, respond to this challenge by releasing inositol phosphates [17]. These data support the idea of the existence of muscarinic-receptor subtypes that selectively interact with either signal-transduction pathway. The recent cloning and expression of genes corresponding presumably to different receptor subtypes has confirmed this assumption. Thus, whereas M1 and M4 receptors efficiently activate PI turnover and poorly regulate AC, M2 and M3 receptors show completely opposite behaviour $[27,28]$. The fact that muscarinic stimulation of Swiss 3T3 fibroblasts induces the release of PCho and significantly inhibits AC, but does not activate PI-specific PLC, permits one to suggest that the muscarinic-receptor subtype responsible for activation of PtdCho-specific PLC is not M1 or M4. Most probably it will be M2, M3 or a still unidentified subtype.

On the other hand, according to the results presented here, muscarinic stimulation appears to be coupled to PtdCho-specific PLC through a G-protein. Evidence for this suggestion is based on the fact that fluoroaluminates are potent activators of this phospholipid-degradative activity and that GTP[S] activates PCho release synergistically with CCho in digitonin-permeabilized cells. In this regard, it should be noted that Irving \& Exton [29] have recently presented experimental evidence showing the existence of a G-protein that couples purinergic stimulation in rat liver membranes to a PtdCho-specific PLC. Interestingly, both G-proteins, that described by Irving \& Exton [29] and that described here, are insensitive to pertussis toxin.

It is also worth noting that the release of PCho to the extracellular medium in muscarinic-stimulated cell occurs without changes in the intracellular levels of this metabolite. Interestingly, Rosoff et al. [14] have shown the sequential activation of extracellular PCho release, followed by an increase in the intracellular levels of this metabolite, in interleukin-1-activated $T$ lymphocytes. Whether changes in both types of PCho may also play different roles in cellular activation is not known. In any case, both types of PCho arise as consequence of PtdCho degradation via PLC [14]. This pathway will produce DAG molecular species different from those originated as a consequence of PI-turnover activation. The stimulation of this novel phospholipid-degradative pathway will occur without changes in intracellular $\mathrm{Ca}^{2+}$ levels. The recent isolation of a cDNA clone encoding a protein kinase activatable by DAG but independent of $\mathrm{Ca}^{2+}[30]$ permit one to speculate on the possible targets of the DAG produced from the activation of PtdCho-specific PLC. On the other hand, the fact that PCho increases in response to muscarinic stimulation are detected only into the extracellular medium might indicate that the DAG produced as consequence of activation of PtdCho hydrolysis may not have access to intracellular PKC. This could mean that this DAG would be acting through PKC-independent routes. All these possibilities are attractive challenges for further research.

This work was supported in part by Grant PB86-0590 from CICYT. M. E. C. and M. L.-B. are Fellows from Comunidad de Madrid and Universidad Complutense respectively.

\section{REFERENCES}

1. Serhan, C. N., Broekman, M. J., Korchak, H. M., Marcus, A. J. \& Weissman, G. (1982) Biochem. Biophys. Res. Commun. 107, 951-958

2. Grzeskowiak, M., Della Bianca, V., De Togni, P., Papini, E. \& Rossi, F. (1985) Biochim. Biophys. Acta 884, 81-90

3. Berridge, M. J. (1987) Annu. Rev. Biochem. 56, 159-193

4. Irvine, R. F., Moor, R. M., Pollock, W. K., Smith, P. M. \& Wreggett, K. A. (1988) Philos. Trans. R. Soc. London B 320, 281-298

5. Nishizuka, Y. (1984) Science 225, 1365-1370

6. Bell, R. L., Kennerly, D. A., Stanford, N. \& Majerus, P. W. (1979) Proc. Natl. Acad. Sci. U.S.A. 76, 3238-3241

7. Moscat, J., Moreno, F., Herrero, C., Iglesias, S. \& GarciaBarreno, P. (1986) Biochem. Biophys. Res. Commun. 139, 1098-1103

8. Watson, S. P., McConnel, R. T. \& Lapetina, E. G. (1984) J. Biol. Chem. 259, 13199-13203

9. Moscat, J., Moreno, F., Iglesias, S., Garcia-Barreno, P. \& Municio, A. M. (1986) Biochem. J. 238, 709-714

10. Berridge, M. J., Heslop, J. P., Irivine, R. F. \& Brown, K. D. (1984) Biochem. Soc. Trans. 13, 67-71

11. Yu, C.-L., Tsai, M.-H. \& Stacy, D. W. (1988) Cell 52, 63-71

12. Bocckino, S. B., Blackmore, P. F. \& Exton, J. H. (1985) J. Biol. Chem. 260, 14201-14207

13. Besterman, J. M., Duronio, Y. \& Cuatrecasas, P. (1986) Proc. Natl. Acad. Sci. U.S.A. 83, 6785-6789

14. Rosoff, P. M., Savage, N. \& Dinarello, C. A. (1988) Cell 54, 73-81 
15. Slivka, S. R., Meier, K. F. \& Insel, P. A. (1988) J. Biol. Chem. 263, 269-272

16. Lacal, J. C., Moscat, J. \& Aaronson, S. A. (1987) Nature (London) 330, 269-272

17. Hepler, J. R., Hughes, A. R. \& Harden, T. K. (1987) Biochem. J. 247, 793-796

18. Yavin, E. (1976) J. Biol. Chem. 251, 1392-1397

19. Bligh, E. \& Dyer, W. (1959) Can. J. Biochem. Physiol. 37, 911-917

20. Neer, E. J. \& Clapham, D. E. (1988) Nature (London) 333, 129-134

21. Marc, S., Leiber, D. \& Harbon, S. (1988) Biochem. J. 255, 705-713

22. Ashkenazy, A., Peralta, E. G., Winslow, J. W., Ramachandran, J. \& Capon, J. D. (1989) Cell 56, 487-493

23. Chiarugi, V. Y., Porciatti, F., Pasquali, F. \& Bruni, P. (1985) Biochem. Biophys. Res. Commun. 132, 900-907
24. Chiarugi, V. P., Pasquali, F., Vannachi, S. \& Ruggiero, M. (1986) Biochem. Biophys. Res. Commun. 141, 591599

25. Kao, L. S. \& Schneider, A. S. (1985) J. Biol. Chem. 260, 2019-2022

26. Chiba, T., Raffoul, K. \& Yamada, T. (1987) J. Biol. Chem. 252, 8467-8469

27. Ashkenazy, A., Winslow, J. W., Peralta, E. G., Peterson, G. L., Schimerlik, M. I., Capon, D. J. \& Ramachandran, J. (1987) Science 238, 672-675

28. Peralta, E. G., Ashkenazi, A., Winslow, J. W., Ramachandran, J. \& Capon, D. J. (1988) Nature (London) 334, 434-437

29. Irving, H. R. \& Exton, J. H. (1987) J. Biol. Chem. 262, 3440-3443

30. Ohno, S., Akita, Y., Konno, Y., Imajoh, S. \& Suzuki, K. (1988) Cell 53, 731-741

Received 6 April 1989/6 June 1989; accepted 15 June 1989 